University of Nebraska - Lincoln

DigitalCommons@University of Nebraska - Lincoln

Faculty Publications from the Harold W. Manter Laboratory of Parasitology

3-1954

\title{
Studies on the Helminth Fauna of Alaska. XX. The Histogenesis of the Alveolar Larva of Echinococcus Species
}

Robert L. Rausch

Arctic Health Research Center, rausch@u.washington.edu

Follow this and additional works at: https://digitalcommons.unl.edu/parasitologyfacpubs

Part of the Parasitology Commons

Rausch, Robert L., "Studies on the Helminth Fauna of Alaska. XX. The Histogenesis of the Alveolar Larva of Echinococcus Species" (1954). Faculty Publications from the Harold W. Manter Laboratory of Parasitology. 558.

https://digitalcommons.unl.edu/parasitologyfacpubs/558

This Article is brought to you for free and open access by the Parasitology, Harold W. Manter Laboratory of at DigitalCommons@University of Nebraska - Lincoln. It has been accepted for inclusion in Faculty Publications from the Harold W. Manter Laboratory of Parasitology by an authorized administrator of DigitalCommons@University of Nebraska - Lincoln. 
Rausch in Journal of Infectious Diseases (March-April 1954) v. 94, no. 2.

Copyright 1954, University of Chicago. Used by permission.

\title{
STUDIES ON THE HELMINTH FAUNA OF ALASKA
}

\author{
XX. THE HISTOGENESIS OF THE ALVEOLAR LARVA OF \\ ECHINOCOCCUS SPECIES
}

\section{ROBERT RAUSCH}

From the Animal-borne Disease Branch, Arctic Health Research Center, Public Health Service, Department of Health, Education, and Welfare, Anchorage, Alaska

The occurrence of the larval stage of Echinococcus granulosus (Batsch, 1786) in a microtine rodent, Clethrionomys rutilus Pallas, on Bering Island was reported by Barabash-Nikiforov (1938) and Afanas'ev (1941). Rausch and Schiller (1951) reported this cestode from tundra voles, Microtus oeconomus Pallas, collected on St. Lawrence Island. Further observations have shown that it occurs also in C. rutilus in the same location. Both species of rodents have a wide circumboreal distribution.

Continued study of this cestode, involving experimental infections of various mammals and comparison with the larval development of $E$. granulosus, has shown it to be specifically distinct. It is differentiated on the basis of the host-species occurrence of the larval stage, and on larval form. Detailed study of the adult cestode did not disclose morphological characters which consistently differentiate it from $E$. granulosus. However, on a morphological basis the adult differs clearly from all material examined excepting specimens from foxes (Alopex and Vulpes) taken on Nunivak Island and along the Arctic Coast of Alaska. Further study of this latter material is required (Rausch, 1952 and 1953).

Received for publication August 12, 1953.

The laboratory infections of the animals used in this work have been established jointly by the writer and Mr. E. L. Schiller. The writer particularly wishes to express appreciation of the assistance of Miss R. V. Sacressen, who prepared the histological material and drew the figures.
Alveolar hydatid disease in man is endemic in southern Europe and in Asia, but the life cycle of the cestode involved has never been completely worked out. The Eurasian form may be identical with that occurring on the Bering Sea islands; however, confirmation will depend upon experimental infections using Eurasian cestode material. Alveolar hydatid disease, apparently first recognized by Virchow (1855), has been studied by several investigators. The work of Dévé and Posselt has been especially important, and the problem has been reviewed in detail by Dardel (1927). Although the writer wishes to point out the possibility that the two forms are conspecific, it is not considered appropriate to review here the voluminous literature concerning alveolar hydatid disease.

It is the purpose of this paper to present a detailed account of the histogenesis of the larval stage of echinococcus species from St. Lawrence Island, based on material derived from laboratory infections.

\section{MATERIAL AND METHODS}

The natural final host of echinococcus species on St. Lawrence Island is the arctic fox, Alopex lagopus L., but sledge dogs are also frequently infected by ingesting rodents harboring larvae. Experimental infections were initially established by feeding infected vole liver to captive arctic foxes. Voles and other rodents were infected at first by feeding gravid segments taken from foxes and dogs autopsied in the field, but the entire cycle was later established in the laboratory.

For the present work, gravid segments of 
echinococcus species taken at autopsy from foxes were used to infect rodents. Immediately after the death of the fox, the intestine was opened and the contents washed out in cold tap water. The cestodes were concentrated by pouring off the supernatant fluid and were freed of debris by repeated washings. The presence of eggs was confirmed by use of a dissecting microscope.

Rodents to be infected were anesthetized with ether, and the eggs administered by means of a glass tube directly into the stomach. Entire gravid segments were introduced, and the number of eggs administered to a single animal ranged from about 400 to 2000 .

This study was based on experimentally induced infections in laboratory-reared field voles, Microtus pennsylvanicus Ord, obtained originally from the eastern United States. For observations on the earlier developmental stages, subadult voles of uniform size were used. No differences in susceptibility or in larval development correlated with age of the host animal have been observed, and both subadult and adult animals have been used in the study of the later stages. Other rodents have been experimentally infected (viz., Ondatra, Peromyscus, Clethrionomys, and other species of Microtus), and comparative observations were made. Only a small amount of human material was available for study.

It was not possible to obtain for comparison early developmental stages of $E$. granulosus larvae, but infective cysts were obtained from naturally infected moose (Alces). Materials from an Australian wallaby (Wallabia) and from man were also compared.

Infected rodents were killed at desired intervals, and tissues were fixed in $10 \%$ formalin or in formalin-acetic acid-alcohol solution. Tissues were embedded by the paraffin method and routinely stained with hematoxylin-eosin and Weigert's iron hematoxylin with van Gieson's picro-acid fuchsin solution counterstain. Special stains were applied in some cases.

\section{RESULTS}

The primary locus of infection in rodents was, without exception, the liver. Larval development in this organ, beginning the first day after infection, is described below for the common field vole, Microtus pennsylvanicus.

At 20 hours.-Necrotic foci up to $140 \mu$ in diameter, involving a relatively few hepatic cells, are visible. There is some leukocytic infiltration, with mac- rophages and a few polymorphonuclear neutrophils. The larvae were not observed.

At 26 hours (fig. 1).--Macroscopically, no changes were visible.

In liver sections, larval loci are disclosed by diffuse leukocytic infiltration into irregularly-shaped areas of necrotic cells. Such cells take a faint stain and show disruption of the nuclear elements. Polymorphonuclear neutrophils are present in good numbers, but more numerous are irregularly-shaped leukocy.tes which may have their origin in the von Kupffer cells of the sinusoids. The larvae, located with difficulty, are situated singly in the masses of necrotic liver cells. They measure about $15 \mu$ in diameter, and consist of spherical masses of cells with prominent, dark-staining nuclei, and pale, acidophilic cytoplasm. The total number of leukocytes is relatively small, and the greatest density occurs in the immediate vicinity of the larvae.

At 48 hours.-The liver is hyperemic, and minute white foci are visible macroscopically.

There is little change in larval size over the previous day. The zone of necrotic liver cells is much larger, and a peripheral zone of degenerating cells is seen around it. Leukocytes are more numerous and are infiltrated over a greater area. It is evident that the larvae have penetrated the walls of the interlobular veins in entering the lobules. The path of migration is densely infiltrated by mononuclear leukocytes.

At 79 hours (fig. 2).-In sections, the larvae are seen as spherical to irregularly shaped vesicles up to $30 \mu$ in diameter. These vesicles are comprised of flat cells with prominent, dark-staining nuclei. The effect on the host tissue is increasingly severe, resulting in an ever enlarging zone of necrotic and degenerating liver cells around each larva. Imme- 
diately around the larvae, polymorphonuclear neutrophils are predominant, but some macrophages are present. Mononuclear cells (apparently lymphocytes) are predominant peripherally and in the areas through which the larvae migrated when entering the lobules. Large numbers of leukocytes are now seen in the blood vessels.

At 96 hours.-Macroscopically, the larvae and surrounding tissue reaction have increased in size, and the liver is hyperemic.

There is some increase in the size of the larval vesicles, but this is not marked. The zone of dense leukocytic infiltration is usually 80 to $100 \mu$ thick, but the zone of degenerating hepatic cells may be much larger. Polymorphonuclear neutrophils comprise almost the entire leukocytic reaction at this time, although a few macrophages are visible. Giant cells are rarely observed.

At 140 hours. - The larval vesicles have increased in diameter up to $50 \mu$. There is little change in the leukocytic barrier, but fibroblasts have appeared peripherally between the degenerating and normal tissue. There is perivascular infiltration of leukocytes involving the interlobular veins.
At 164 hours.-Macroscopically, the superficial foci have increased in size.

The larval vesicles have attained a diameter of as much as $70 \mu$. Eosinophils are numerous in the vicinity of the larvae. Each larval vesicle is surrounded by a dense zone of leukocytes about $40 \mu$ thick. Beyond this, necrotic and degenerating hepatic cells form another zone, and the whole is surrounded by fibroblasts to a depth of about $20 \mu$. Some fibrosis has taken place, and there is an abrupt transition from degenerating to normal liver cells. The path of larval migration is still infiltrated by leukocytes.

At 212 hours (fig. 3).-The primary vesicles show a slight thickening of the germinal layer. A large proportion of them contain secondary vesicles which have originated by endogenous budding, and secondary vesicles are being produced also by exogenous budding. In the latter cases, extensions from the germinal membrane invade the connective tissue adventitia, vacuolate, and increase in size. In such cases leukocytes (mainly polymorphonuclear neutrophils) surround the secondary vesicle, and persist as it increases in size. These cells are eventually trapped be-

FIG. 1-8.-The symbols designate the following structures: NHC, normal hepatic cell; DHC, degenerating hepatic cell; GM, germinal membrane; NGM, nucleus of germinal membrane; PV, primary vesicle; ENV, larval vesicle of endogenous origin; EXV, larval vesicle of exogenous origin; DS, developing scolices; SGM, subgerminal membrane; CC, calcareous corpuscles; $\mathrm{S}$, scolices.

Fig. 1.-Embryo at 26 hours after infection. From $10 \mu$ section stained with hematoxylin-eosin.

Fig. 2.-Primary larval vesicle at 79 hours after infection. From $\cdot 10 \mu$ section, stained with hematoxylin-eosin.

FIG. 3.-Primary vesicle with secondary vesicle of exogenous origin at 212 hours after infection. From $6 \mu$ section stained with hematoxylin-eosin.

FIG. 4.- Larval mass, at 287 hours after infection, showing vesicles both of endogenous and exogenous origin. From $10 \mu$ section, stained with Weigert's hematoxylin and van Gieson's counterstain.

Fig. 5.-Alveolar form of larva at 336 hours after infection. The primary vesicle can no longer be identified, and both endogenous and exogenous development of secondary vesicles are taking place. From $6 \mu$ section, stained with Weigert's hematoxylin and van Gieson's counterstain.

FIG. 6.-Detail of larval vesicles at 45 days after infection. A few scolices are being produced, and both endogenous and exogenous development of secondary vesicles are continuing. From $10 \mu$ section stained with hematoxylin-eosin. 
Rausch in Journal of Infectious Diseases (March-April 1954) v. 94, no. 2.

Copyright 1954, University of Chicago. Used by permission.
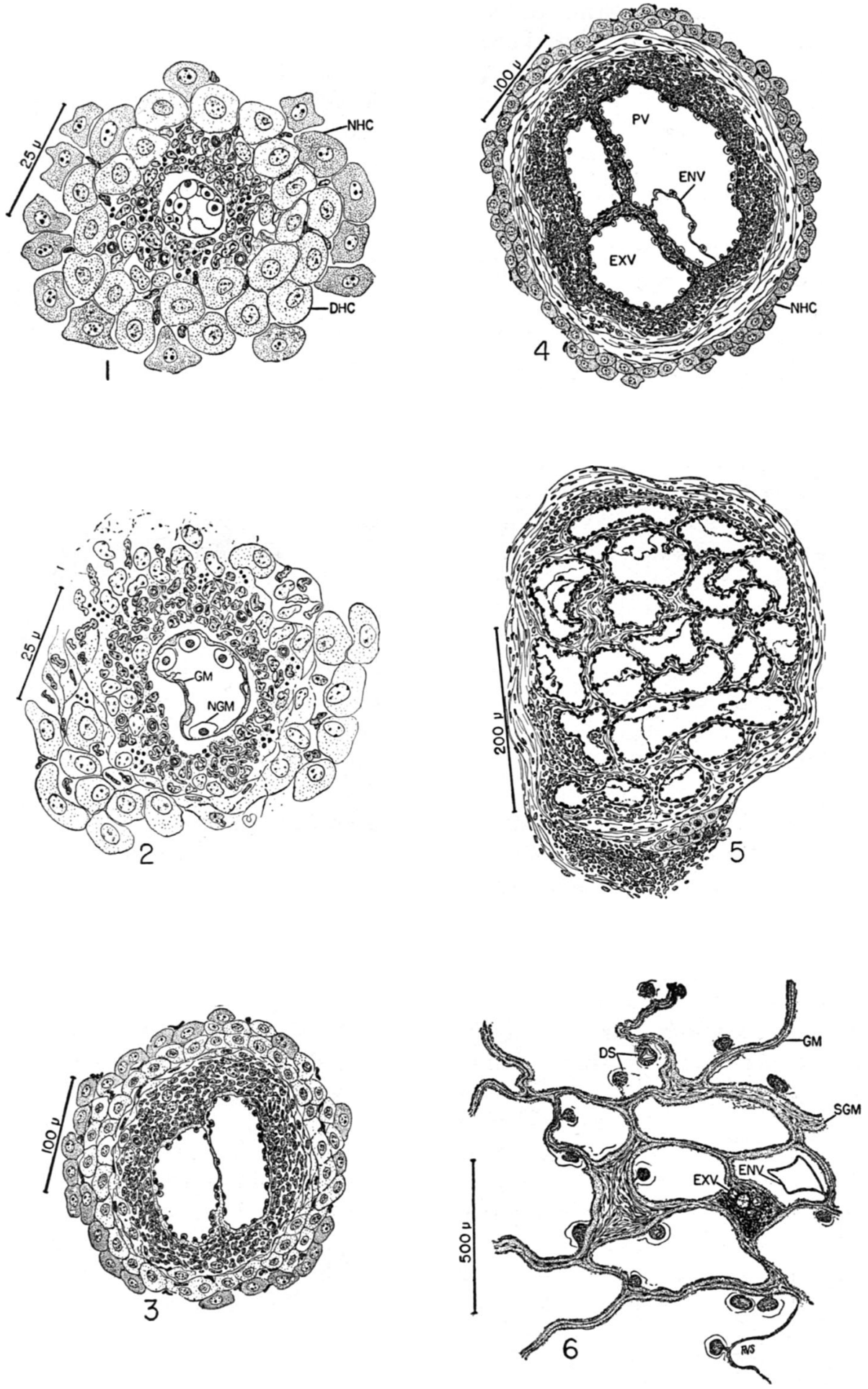

Figures 1-6 
tween two layers of germinal membrane as the vesicles grow and become contiguous. Frequently the loci of two primary vesicles may be closely apposed, but these are easily differentiated from secondary vesicles by their thick connective tissue encapsulation.

At 234 hours.-Macroscopically, it is is possible to differentiate the larval vesicles from the surrounding tissue reaction when they are superficially located. Gross specimens which have been stained and cleared show that genesis of secondary vesicles has occurred in the majority of the larvae.

Microscopically, there is little change visible beyond continued growth and proliferation of secondary vesicles. Cellular characteristics are unchanged. The path of larval migration remains densely infiltrated by mononuclear cells. Perivascular infiltration by such cells is marked insofar as the interlobular veins are concerned. Central veins do not show this.

At 287 hours (fig. 4.) - There is continued growth and proliferation of secondary vesicles, and several may develop simultaneously in the connective tissue capsule of a single larva.

A tendency toward the later alveolar structure is now evident. There is little change in the arrangement and composition of the cells surrounding the larval masses. Immediately surrounding the germinal membrane are seen polymorphonuclear neutrophils, macrophages, and a few eosinophils. A well-formed connective tissue layer is next, bordering directly upon the hepatic cells. There is evidence of pressure atrophy of the latter. Foci of mononuclear cells occur irregularly and are apparently associated with the damage caused by larval migration.

At 336 hours (14 days) (fig. 5). - The liver is enlarged and the vesicles are prominent. The separate larval masses have a diameter of 500 to $1500 \mu$.

Very rapid larval growth has occurred during the last two days. This is evidenced by a relatively great increase in size of the larval mass and by the presence of many secondary vesicles. The connective tissue capsule, previously dense and well-formed, has been disrupted, with the result that the stroma supporting the larval vesicles is in direct contact with the liver cells. There is a marked increase in vascularity. There is also some proliferation of the bile ducts. The zone of liver cells showing pressure atrophy is larger. The sinusoids are distended, and the entire organ is very hyperemic. The numerous larval vesicles are supported by a loose, fibrous stroma. Around the periphery of the mass, mononuclear cells are predominant, and have infiltrated the hepatic cells. Either singly or in small groups, hepatic cells have been surrounded and isolated by the leukocytes, so that necrotic and degenerating cells are numerous within the periphery of the larval mass. The stroma itself contains many leukocytes in the more peripheral parts. Polymorphonuclear neutrophils are most abundant, but eosinophils are also present. Toward the center of the larval mass the leukocytes are fewer. The presence of disrupted nuclear components and other debris indicates that they are being destroyed in the course of larval development.

There is little change in the appearance of the vesicles. There is, however, a thickening of the germinal membrane. There is no evidence yet of the development of a subgerminal ("laminated") membrane. Rapid larval growth is also indicated by the presence, at the edge of the stroma, of numerous isolated masses of germinal tissue which are the forerunners of new vesicles. There is less endogenous larval development, but 
some of the larger vesicles show this process.

At 20 days. - The superficially located larvae, up to $3 \mathrm{~mm}$ in diameter, are seen as coalesced aggregations of translucent vesicles. The liver is hyperemic, and collateral circulation is developing. This is seen particularly as a proliferation of the superficial branches of the interlobular veins, with numerous anastomoses in the immediate vicinity of the vesicles.

Microscopically, there is increase in vesicle size. Pressure atrophy of the liver cells is particularly evident. The sinusoids are distended with erythrocytes, and there is marked dilatation of the central veins. There has been a reduction in the number of leukocytes. Polymorphonuclear neutrophils are abundant in the immediate vicinity of the vesicles, and mononuclear cells are still moderately numerous around the periphery. The germinal membrane is relatively thick, but there is no evidence of early scolex development. The subgerminal membrane is well developed. There is a narrow zone of fibroblastic proliferation, with numerous collagenous fibers.

At 27 days. - There is a continuing increase in vesicle size and number, with a corresponding increase in the size of the infected organ.

Sections show that almost all cellular elements of host-tissue origin have been eliminated from within the mass of vesicles. The larval mass has assumed an alveolar structure and is comprised of great numbers of contiguous and interconnected vesicles. There is no evidence of scolex formation. Outside the subgerminal layer is a very thin, but dense, connective tissue barrier separating the parasite tissue from the host tissue. All visible hepatic cells show pressure atrophy, probably resulting from the combined pressures of the rapidly grow- ing vesicles and the greatly distended sinusoids.

At 34 days.-Atrophy of the hepatic cells is marked. There appears to be breaking down of the erythrocytes in the sinusoids. A thin zone of collagenous fibers separates the subgerminal membrane from the hepatic tissue. A very thin zone of leukocytes, mainly polymorphonuclear neutrophils, is found immediately adjacent to the subgerminal membrane. The germinal membrane is loosely arranged and is relatively thick. A few scolices are seen, in the early stages of development.

At 45 days (fig. 6).-Macroscopically, the size of the liver is greatly increased over normal. The vesicles show a tendency to become confluent.

There is continued growth of larval vesicles. Scolex development is progressing, but none is fully developed and infective. The remaining hepatic tissue is being destroyed.

At 50 to 150 days.-During this time there is a great increase in size of the infected liver. Large collateral blood vessels become prominent on the surface and the amount of visible liver tissue is becoming progressively less.

Microscopically, there is an increase in the amount of parasite tissue, with a progressive destruction of the remaining liver tissue. The branches of the portal vein are dilated, and the sinusoids of the remaining liver tissue are greatly congested. The central veins also show dilation, but not to the extent that perivascular necrosis results. Pressure atrophy of hepatic cells is general; there is also some necrosis resulting from the effect of toxic products elaborated by the parasites. During this time scolex production goes on rapidly; at first there are only a few scolices, widely scattered over the germinal membrane lining the vesicles, but later the vesicles are nearly filled by them. The vesicles are 


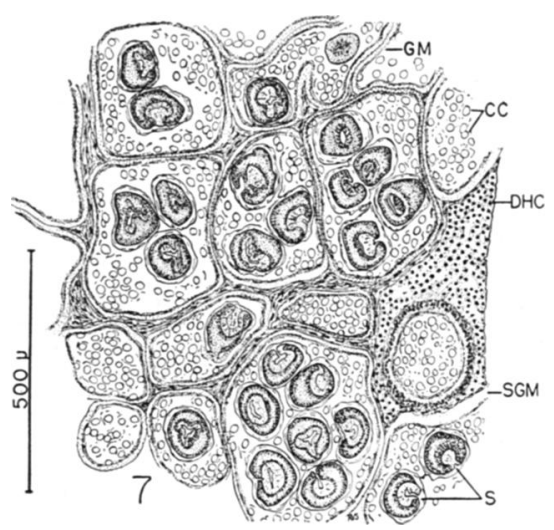

FIG. 7.-Structure of larval mass 5 months after infection. Infective scolices are abundant and little hepatic tissue remains.

not fluid-filled, as is characteristic of E. granulosus. The subgerminal membrane is well developed, averaging 10 to $12 \mu$ thick. It may, however, show undulations and thickened areas. Beneath it, a dense layer of connective tissue, from a few up to $100 \mu$ thick, surrounds individual vesicles and forms barriers between them and the remaining liver tissue. The importance of leukocytes becomes progressively less. Finally, only a few scattered polymorphonuclear neutrophils may be seen along the subgerminal membrane.

At 150 to 170 days (fig. 7 and 8).The infected liver attains maximum size and death of the host may occur. The living animal is dyspneic and slow of movement. The infected liver may constitute two-thirds of the total weight of the animal. Nothing but parasite tissue may be visible, but the cut surface may show a few islets of liver cells still recognizable macroscopically as such.

Microscopically, the vesicles are filled with infective scolices. Calcareous corpuscles are abundant. There is a tendency toward a radial arrangement of the walls of the secondary vesicles, and it is usually possible to recognize units of vesicles which have developed from the original embryo. The individual vesicles are usually less than $10 \mathrm{~mm}$ in diameter. Sections show a follicular appearance of the larval mass, but there is a tendency for the aggregations of vesicles to become confluent; this is best seen in cleared, gross sections. The aggregations of vesicles which have originated from a single embryo contain few or no elements of host-tissue origin. In rare instances, there may be isolated remnants of hepatic cells or a few leukocytes. Frequently, however, such tissue elements are entrapped when the larval aggregations become confluent. These undergo destruction, and no normal hepatic tissue is visible. There is a reduction in the amount of connective tissue around the larval mass, as a result of the rapid larval growth. Apparently by this time the host body is no longer capable of utilizing its defense mechanisms.

Changes in the cellular components of the circulating blood.-Significant changes in the cellular composition of the circu-

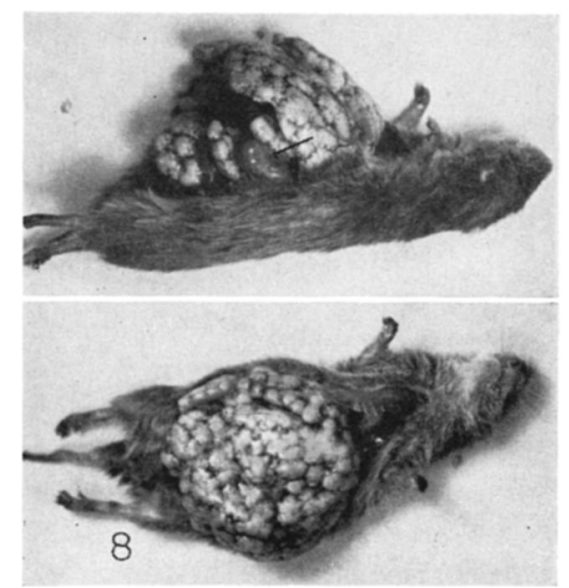

FIG. 8.-A heavily infected field vole killed in the terminal stages of disease 5 months after infection. The animal weighed $98.0 \mathrm{~g}$; of this, the infected liver weighed $59.1 \mathrm{~g}$, with a volume of $60 \mathrm{cc}$. The maximum normal weight for this species of vole rarely exceeds $60 \mathrm{~g}$. The arrow indicates the position of the stomach and duodenum. 
lating blood were not observed in smears stained with Wright's stain. Even in the terminal stages, about 5 months after infection, there was no eosinophilia.

Larval development in other rodent species.-Comparative study of infections in other species of microtine rodents failed to disclose any differences in larval development. In a few cases vesicles of unusual size (up to $20 \mathrm{~mm}$ ) developed, along with those of more typical appearance, but this was also observed in the common field vole.

Metastatic spread of larvae.-In both natural and experimental infections of long duration, secondary foci of infection in the spleen, mesentery, peritoneum, etc. were frequently observed. These originated through metastasis. The dilatation of blood vessels resulting from the larval growth apparently is adequate to allow bits of larval tissue to pass through into the hepatic vein and thence into the systemic circulation. It is probable that such larval tissue originates as exogenous buds which gain entrance to the blood stream by perforation of a vessel wall.

Intra-abdominal larval development.A very small quantity of germinal membrane containing a few scolices was injected through an 18-gauge needle into the abdominal cavity of a subadult vole. This animal, as a large, breeding male, was killed 160 days later. An ovoid mass of larval vesicles, measuring $10 \times 15$ $\mathrm{mm}$, was found free in the abdominal cavity.

Microscopically, it was evident that development was not entirely normal. The mass consisted essentially of proliferated subgerminal membrane tissue, in which there were large calcified areas. Normal-appearing vesicles were present only peripherally, and these were lined with scolices which appeared to be completely developed and infective. No cellular components of host-tissue origin were recognized. It is indicated from this that the main function of the subgerminal membrane is supportive, and that it may proliferate extensively under some circumstances.

\section{DISCUSSION}

The intermediate stage of E. granulosus occurs mainly in perissodactyls and artiodactyls. Durie and Riek (1952) reported wallabies (Thylogale and Wallabia) to be important intermediate hosts in Australia. As far as the writer has been able to determine, however, rodents rarely harbor the intermediate stage of E. granulosus. Certain rodents (e.g., Myocastor) have been reported as harboring echinococcus larvae, but the species involved is probably not $E$. granulosus (Rausch, 1953). It is concluded that in this case host-species occurrence is significant, since it has not been possible to infect microtine rodents with $E$. granulosis in the laboratory. It cannot be considered that larval form is influenced by abnormal host-species occurrence.

Various authors have described the slow rate of development of E. granulosus larvae in sheep and swine. Dew (1925) reported a vesicle diameter of 40 to $50 \mathrm{~mm}$ in swine at the end of 3 months after infection. With a vesicle diameter of $100 \mathrm{~mm}$ there was no development of scolices at the end of 5 months. Turner et al (1937) rarely observed cysts $1.0 \mathrm{~cm}$ in diameter 11 or twelve months after infection of experimentally infected sheep. Earlier workers, including Dévé and Leuckart, obtained similar results. In Alaska, larval vesicles containing matured scolices in naturally-infected moose (Alces) rarely exceeded $60 \mathrm{~mm}$ in diameter. All North American specimens of E. granulosus larvae examined by the writer from naturally infected cervids have con- 
sisted of simple, fluid-filled cysts surrounded by a dense connective tissue layer.

Dew (1925) observed that the larvae of $E$. granulosus become vesicular and somewhat enlarged at 14 days. The larvae of the St. Lawrence Island cestode are vesicular 3 days after infection. Dew found that the entire larval follicle, including the total tissue reaction, measured but 250 to $350 \mu$ at the end of 3 weeks. The aggregation of larval vesicles of the St. Lawrence Island form averages about $3 \mathrm{~mm}$ in diameter at 21 days. The thick connective tissue capsule surrounding the larval vesicle of $E$. granulosus is also indicative of slow growth. As mentioned earlier in this paper, no such well-developed connective tissue capsule is seen associated with the later larval stages of the St. Lawrence Island cestode.

The proliferation of secondary vesicles is essentially endogenous insofar as E. granulosus is concerned, or, at best, exogenous production is infrequent. The mechanism of secondary cyst formation has been reviewed by Dew (1926). He concluded that true exogenous development of secondary vesicles does not occur, and in this he disagreed with several earlier writers.

\section{CONCLUSIONS}

The larva of the St. Lawrence Island cestode attains its alveolar form by means of a rapid rate of proliferation of exogenous secondary vesicles. This also explains its ability to invade host tissue so rapidly, and with such a malignant effect. It is concluded, then, that ability in the St. Lawrence Island cestode to produce secondary vesicles exogenously constitutes the main difference between its larval development and that of Echinococcus granulosus.

\section{REFERENCES}

Afanas'ev, V. P. 1941, Parazitofauna promyslovykh mlekopitaiushchikh Komandorskikh Ostrovov. Uchenie Zapiski, Seriia biologicheskikh Nauk. 18: 93-117.

Barabash-Nikiforov, I. 1938, Mammals of the Commander Islands and the surrounding sea. J. Mammal. 19: 423-429.

Dardel, G. 1927, Das Blasenwurmleiden in der Schweiz, Bern, 105 pp.

Dew, H. R. 1925, The histogenesis of the hydatid parasite (Taenia echinococcus) in the pig. Med. J. Australia 1 : 101-110.

. 1926, The mechanism of daughter cyst formation in hydatid disease. Med. J. Australia 1: 451-460.

Durie, P. H. and Riek, R. F. 1952, The role of the dingo and wallaby in the infestation of cattle with hydatids (Echinococcus granulosus (Batsch, 1786) Rudolphi, 1805) in Queensland. Med. J. Australia 28: 249-254.

Rausch, R. 1952, Hydatid disease in boreal regions. Arctic 5: 157-174.

- 1953, The taxonomic value and variability of certain structures in the cestode genus Echinococcus (Rud., 1801), and a review of recognized species. Commemoration vol. for Dr. G. S. Thapar. Lucknow, India. In press.

Rausch, R. and Schiller, E. L. 1951, Hydatid disease (Echinococcosis) in Alaska and the importance of rodent intermediate hosts. Science 113: 57-58.

Turner, E. L., Dennis, E. W. and Berberian, D. A. 1937, The production of artificial immunity against hydatid disease in sheep. J. Parasitol. 23: 43-61.

Virchow, R. 1855, Die multiloculäre, ulcerirende Echinokokkengeschwulst der Leber. Verh. phys.-med. Ges. Würzb. 6: 84-95. 